\title{
Normothermic Ex Vivo Lung Perfusion in Clinical Lung Transplantation
}

\author{
Jonathan C. Yeung ${ }^{1} \cdot$ Shaf Keshavjee $^{1}$
}

Published online: 10 October 2015

(C) Springer International Publishing AG 2015

\begin{abstract}
Normothermic ex vivo lung perfusion is a novel strategy of donor lung preservation that preserves the metabolic activity of the organ. There are therefore opportunities for further lung evaluation and therapeutic intervention during the ex vivo stage. We review our clinical experience with this technique and offer perspectives for future development.
\end{abstract}

Keywords Normothermic ex vivo lung perfusion · Clinical lung transplantation

\section{Introduction}

With the many successes achieved in clinical lung transplantation over the last 30 years, the demand for lung transplantation around the world has continued to increase. Unfortunately, the supply of acceptable donor organs remains extremely limited not only due to the inadequate absolute number of organ donors but also because the utilization rate of available donor lungs is only in the range of $15-20 \%$ [1]. The large majority of donor lungs are rejected due to injuries sustained during complications of brain death and intensive care. The consequence is that wait-list mortality can be as high as 15 $25 \%[2]$.

This article is part of the Topical Collection on Thoracic Transplantation

Shaf Keshavjee

shaf.keshavjee@uhn.ca

1 Division of Thoracic Surgery, Toronto Lung Transplant Program, Toronto General Hospital, University of Toronto, 200 Elizabeth Street, 9N946, Toronto, ON M5G 2C4, Canada
The low utilization rate presents a unique opportunity to expand the donor pool. Given the large number of rejected donor organs, improved utilization alone could largely meet the current organ demand. Ex vivo lung perfusion (EVLP) demonstrates promise towards realizing this goal. Improved evaluation using EVLP will provide clinicians with more confidence to utilize questionable organs, and EVLP-based treatment strategies will allow the use of organs currently deemed too injured to be safely transplanted.

In this article, we will review the early development of EVLP, the current state-of-the-art, and future directions for this technology.

\section{Background}

The primary strategy for solid organ preservation today, including lung, is that of cold static preservation [3]. Central to this strategy is the use of hypothermia to reduce cellular metabolic activity in order to maintain cellular viability. The consequence is that it precludes any meaningful lung evaluation or manipulation during the preservation phase. Ex vivo lung perfusion represents a different paradigm of lung preservation where the maintenance of metabolic activity and organ function is a primary goal. Indeed, the concept of warm ex vivo perfusion as a preservation strategy is not a new one. As early as 1935, Carrel and colleagues proposed "whole-organ culture" as a means of preserving donor solid organs for transplantation [4]. Jirsch et al., in 1970, attempted to preserve and evaluate lungs in this manner for cases of distant procurement [5]. In both eras, attempts failed due to the inability to maintain the air-fluid barrier of the lung, leading to the development of edema. Essentially, further injury to the donor lung was being inflicted by the perfusion circuit and technique itself. 


\section{Modern Ex Vivo Lung Perfusion Strategies}

In the modern era, ex vivo lung perfusion was revisited by Steen in Sweden. Using a buffered extracellular type solution with an optimized colloid osmotic pressure (Steen solution) combined with blood as the lung perfusate, Steen performed short-term perfusion for ex vivo evaluation of lungs donated following uncontrolled cardiac death (DCD) [6-9]. Since the ultimate goal of Steen's studies was to utilize EVLP for functional lung evaluation, the perfusion times were short $(1 \mathrm{~h})$.

Erasmus et al. were able to extend EVLP to $6 \mathrm{~h}$ before circuit-induced injury became apparent [10]. In order for EVLP to serve not only as a platform for lung evaluation but also as a platform for the delivery of therapeutic strategies, stable, and reliable EVLP for longer periods beyond $1 \mathrm{~h}$ would be needed. Our group in Toronto was able to extend this to beyond $12 \mathrm{~h}$ by implementing four key lung protective strategies [11]. First, we utilized an acellular perfusate. Prior studies from Egan's group had shown that mere ventilation of a donor lung was adequate to preserve cell viability in nonperfused lungs [12]. Indeed, we have found that the continuous oxygenation of the acellular perfusate by ventilation of the lung provides ample oxygen delivery to the ex vivo lung with preservation of function over $12 \mathrm{~h}$ of EVLP. This avoids the problem of a limited lifespan of red blood cells within the harsh perfusion environment and the resultant production of pro-inflammatory RBC breakdown products [13]. It also significantly simplifies clinical use. Second, we chose to perfuse the lungs at $40 \%$ of the estimated cardiac output. This lower flow rate reduces the hydrostatic pressure stress, and consequently, the development of edema. Third, we believe that maintenance of a positive left atrial pressure of around 3$5 \mathrm{mmHg}$ is vital to long-term EVLP. This small but positive LA pressure tents open the distal veins and prevent collapse of the veins from occurring during decreases of flow during alveolar expansion at inspiration [14]. The absence of positive LA pressures can also lead to unstable alveolar geometry and result in decreased lung compliance [15]. Indeed, we have recently demonstrated, in a porcine model, lung deterioration by $6 \mathrm{~h}$ of EVLP in cases where the left atrium was left open [16]. Finally, the use of a centrifugal pump is felt to be helpful. With each breath, distension of the alveoli will apply pressure to the peri-alveolar vessels, increasing the pulmonary vascular pressure slightly. As a consequence of how a centrifugal pump functions, increased resistance to the pump will result in decreased rotation and flow. Thus, the pump will back off during times of increased pulmonary vascular resistance rather than force fluid through, potentially causing injury or edema.

Our strategy is described in detail elsewhere [11]. In brief, the Toronto EVLP System is composed of a circuit with a centrifugal pump, a leukocyte filter, a hollow-fiber oxygenator heat exchanger, and a hardshell reservoir. It is primed with $2 \mathrm{~L}$ of Steen solution (XVIVO Perfusion, Denver CO), $500 \mathrm{mg}$ methylprednisolone (Solu-medrol; Sandoz Canada, Boucherville, Canada), 3000 IU of unfractionated heparin (Organon, Canada), and antibiotic (500 $\mathrm{mg}$ imipenem/cilastatin, Primaxin; Merck, Whitehouse Station, NJ). Following cannulation of the donor lungs, a 1-h graduated warm up and stepwise increase in perfusion flow is started. The lungs are perfused at $10 \%$ of the targeted flow at room temperature for the first $10 \mathrm{~min}$. At $10 \mathrm{~min}$, the flow is raised to $20 \%$ of targeted flow and the perfusate temperature is increased to $30^{\circ} \mathrm{C}$. At $20 \mathrm{~min}$, the temperature is raised to $37^{\circ} \mathrm{C}$ and the flow increased to $30 \%$ of target. Ventilation is started $(7 \mathrm{~mL} / \mathrm{kg}$, PEEP $5 \mathrm{~cm} \mathrm{H}_{2} \mathrm{O}$, and 7 cycles/min) when the temperature reaches $33{ }^{\circ} \mathrm{C}$. Once the lungs are being ventilated, the gas mixture to the oxygenator $\left(86 \% \mathrm{~N}_{2}, 8 \% \mathrm{CO}_{2}\right.$, and $\left.6 \% \mathrm{O}_{2}\right)$ is turned on at a sweep of $1 \mathrm{~L} / \mathrm{min}$ for a post-membrane $\mathrm{pCO}_{2}$ of around $35-40 \mathrm{mmHg}$. The flow is then increased to $30,50,80$, and finally $100 \%$ of target at the subsequent 10 -min intervals. The left atrial pressure is carefully maintained at $3-5 \mathrm{mmHg}$ by adjusting the height of the reservoir.

Adequate feedback to the surgeon about the function of the lung during EVLP is as important as the perfusion strategy itself. Given that the end phenotypic result of lung injury is the development of pulmonary edema, the evaluation strategy is based on serial observation for changes in lung physiologic parameters. Lung compliance and airway pressure are measured at each hour. Increasing pulmonary edema will decrease compliance and increase airway pressure, and thus the trends in these parameters are more important than the individual measurements themselves. Thus, we currently perfuse lungs for a minimum of $4 \mathrm{~h}$ before a final decision is made for transplantation. $\mathrm{PO}_{2}$ is a vital parameter for in vivo assessment; however, due to the use of an acellular perfusate, $\mathrm{pO}_{2}$ can be a less sensitive measure of lung injury and a deteriorating $\mathrm{pO}_{2}$ is considered a late sign of lung dysfunction [17]. In addition to physiologic measurements, we also routinely assess the donor lung during EVLP with sequential lung radiographs and bronchoscopic examination.

The Toronto EVLP technique is only one strategy of EVLP to evolve from pre-clinical studies. Others have used different techniques and devices for ex vivo lung perfusion with varying results. Based on Steen's initial work, the Lund technique utilizes an open atrium, a cellular perfusate, and perfusion at full estimated cardiac output. Their strategy is detailed elsewhere [18]. Wallinder et al. report on 11 EVLPs over an 18month period using this technique [19]. While in-hospital stay was similar to their contemporaneous lung transplant controls, ICU length of stay and time on mechanical ventilation was actually found to be longer in their EVLP group. The DEVELOP-UK (Vivoline) trial using this technique has recently been prematurely terminated, and publication of the results is pending.

The OCS Lung system (Transmedics) is another EVLP strategy, unique in that it is a mobile system where donor 
lungs are perfused immediately after retrieval and transported perfused to the implantation center. This EVLP strategy is predicated upon the theory that any amount of cold ischemia is damaging to the donor lung. However, there has not been any experimental or clinical evidence to support this theory as of yet. Indeed, Mulloy et al. demonstrate superior lung function in a DCD porcine model following the addition of cold static preservation when compared to total normothermic perfusion for the same period of time [20]. We have not observed a negative impact on patient outcomes with prolonged static cold preservation times preceding or following our EVLP treatment. The ongoing INSPIRE and EXPAND Transmedics trials will further explore this strategy in standard and extended criteria lungs, respectively. However, unfortunately, neither of these trials is designed to answer this question. As the control group does not ever undergo EVLP, it will remain unclear if minimizing pre-EVLP cold ischemic time is beneficial. The users of this technology will need to decide if the additional logistical challenges and expense is worth the presumed benefits.

\section{Clinical Results}

Using the Toronto EVLP strategy outlined above, we published the outcomes of the first clinical trial, the Human Ex Vivo Lung Perfusion (HELP) trial, in 2011 [21]. Out of 23 high risk donors, 20 were evaluated on EVLP to be appropriate for transplantation. Using these extended donor lungs, no differences in the rate of PGD, days on mechanical ventilation after transplant, ICU stay, hospital stay, or 30-day mortality were found when compared to contemporary transplantation using traditionally accepted donors. These results have held true in long-term follow-up of over 60 transplanted EVLP lungs $[22,23]$. Our technique has proven to be reproducible in centers around the world. Aigner et al. published the Vienna experience in 2012 where they describe the results of nine EVLP double lung transplants with similar outcomes to their conventional transplant population [24]. The NOVEL trial is the first prospective multicenter trial to evaluate EVLP. Out of 42 EVLP lungs and 42 controls, early and midterm results between patients that received EVLP and standard criteria lungs are equivalent, despite all EVLP lungs being initially rejected as unsuitable for transplantation [25].

More exciting are the early gains in donor yield that have come with EVLP. The use of EVLP was responsible for a $28 \%$ increase in lung transplant activity at our center. These early gains have been largely due to the superior evaluation of donor lungs on EVLP. The objective and serial evaluation which can occur during EVLP has provided clinicians the confidence to transplant previously questionable organs. Indeed, due to the inherent difficulty of assessing function in the donor, improved lung evaluation would likely greatly expand the use of donation after cardiac death (DCD) lungs. Around $10-15 \%$ of our recent lung transplant volume now comes from DCD lungs, with posttransplant outcomes similar to lungs from brain dead donors. Though we and others have previously utilized DCD organs successfully without EVLP evaluation, $50 \%$ of our DCD lungs have been further evaluated with EVLP prior to transplantation in our most recent series [26]. Whether EVLP should be routinely utilized for evaluation of DCD lungs remains to be determined.

Currently, two trials using the Toronto technique are ongoing: the Vienna trial and the Perfusix trial. The Vienna trial is randomizing standard criteria lungs between EVLP and standard preservation. Until now, studies using the Toronto technique have perfused only extended criteria lungs and the Vienna study will explore the potential of additional benefit of EVLP on "acceptable lungs". The Perfusix trial will explore the use of centralized centers for EVLP. Rather than develop EVLP expertise at each individual transplant center, centralization of equipment, personnel, and expertise in strategic geographical locations may be able to serve the EVLP need of multiple transplant centers.

\section{Future Directions}

EVLP offers an unprecedented opportunity for the therapeutic manipulation of donor lungs prior to transplantation. Already, strategies using existing therapies such as thrombolytic treatment for lungs affected by pulmonary emboli have been successfully employed [27, 28]. Employment of other drugs during EVLP such as antibiotics for lungs rejected due to pneumonia, surfactant for lungs injured by aspiration, and terbutaline for edematous lungs remains under study [29-31]. One major advantage of therapy during EVLP is that the lungs are isolated from other organs, and thus medication doses otherwise harmful to other organs can be utilized. In addition, the lack of hepatic and renal clearance mechanisms will lead to prolonged half-lives of most therapeutic agents. We have harnessed these unique EVLP characteristics to develop a clinically applicable gene therapeutic strategy for donor lungs. Using rat and pig models of lung transplantation, we first demonstrated benefit of IL-10 gene therapy to donor lungs $[32,33]$. We then showed that the metabolic activity and the $12 \mathrm{~h}$ of stability provided by EVLP were adequate for gene expression prior to transplantation $[34,35]$. Finally, we demonstrated that the isolation of donor lungs from the circulating immune system during EVLP mitigated vector-associated inflammation, a major concern of gene therapy [36, 37]. These unique aspects of EVLP can likely be exploited for other therapeutic and regenerative strategies, including stem cell therapies. A solitary treatment strategy for all lung injury is unlikely to exist. More likely, we will start treating donor lungs using a "personalized approach"-like we do patients; 
identify the illness and deliver a therapy targeted to that illness. Establishing an EVLP treatment arsenal for the various important donor lung injuries will be a target for research in the future.

Rapid diagnosis as well as feedback regarding success or failure of therapy will be vital to transplant decision-making and thus developments in evaluation strategies will also be required in the near future. Many potential biomarkers have been previously identified to distinguish between injured lungs and good lungs. These have included cytokine profiles such as IL-6/IL-10 ratio and gene expression signatures [38-40]. However, their clinical employment has been limited due to the timeframe needed to obtain a result. New developments in rapid protein and gene detection may 1 day provide real-time readouts of therapeutic effects at the molecular level [41], for example, visualizing a fall in IL-6 production following IL-10 gene therapy.

Another future avenue of study will be to better understand the effect of EVLP itself on the donor lung. Though we have achieved physiologic stability during $12 \mathrm{~h}$ of EVLP, it is unlikely that the lung is stable at a cellular level. We have begun to study the gene expression changes occurring during EVLP and have seen gene expression signatures pointing towards decreased inflammation and increased regeneration by $6 \mathrm{~h}$ of EVLP [42]. We have also explored the metabolic changes occurring during EVLP in perfusate metabolite levels and found marked changes in glycolysis, tricarboxylic acid cycle, and fatty acid beta-oxidation metabolism at $4 \mathrm{~h}$ of EVLP [43]. A better understanding of these processes will ultimately allow us to extend EVLP to a timeframe of days to weeks.

\section{Conclusions}

EVLP is a novel strategy for lung preservation which facilitates donor lung evaluation, intervention, and recovery. Clinical outcomes following EVLP and lung transplantation have been equivalent or superior to conventional lung transplantation despite the use of marginal donor organs. More importantly, centers using EVLP have been able to increase their lung transplant activity. We anticipate that future development of EVLP treatment strategies will ultimately allow for the use of the majority of the existing donor pool and eliminate waitlist mortality.

\section{Compliance with Ethics Guidelines}

Conflict of Interest Jonathan C. Yeung and Shaf Keshavjee declare that they have no conflict of interest.

Human and Animal Rights and Informed Consent This article does not contain any studies with human or animal subjects performed by any of the authors.

\section{References}

1. Klein AS, Messersmith EE, Ratner LE, Kochik R, Baliga PK, Ojo AO. Organ donation and utilization in the united states, 1999-2008. Am J Transplant. 2010;10(4 Pt 2):973-86.

2. Keeshan BC, Rossano JW, Beck N, et al. Lung transplant waitlist mortality: height as a predictor of poor outcomes. Pediatr Transplant. 2015;19(3):294-300.

3. Southard JH, Belzer FO. Organ preservation. Annu Rev Med. 1995;46:235-47.

4. Carrel A, Lindbergh CA. The culture of whole organs. Science. 1935;81(2112):621-3.

5. Jirsch DW, Fisk RL, Couves CM. Ex vivo evaluation of stored lungs. Ann Thorac Surg. 1970;10(2):163-8.

6. Steen S, Sjoberg T, Pierre L, Liao Q, Eriksson L, Algotsson L. Transplantation of lungs from a non-heart-beating donor. Lancet. 2001;357(9259):825-9.

7. Steen S, Liao Q, Wierup PN, Bolys R, Pierre L, Sjoberg T. Transplantation of lungs from non-heart-beating donors after functional assessment ex vivo. Ann Thorac Surg. 2003;76(1):244-52. discussion 252

8. Steen S, Ingemansson R, Eriksson L, et al. First human transplantation of a nonacceptable donor lung after reconditioning ex vivo. Ann Thorac Surg. 2007;83(6):2191-4.

9. Ingemansson R, Eyjolfsson A, Mared L, et al. Clinical transplantation of initially rejected donor lungs after reconditioning ex vivo. Ann Thorac Surg. 2009;87(1):255-60.

10. Erasmus ME, Fernhout MH, Elstrodt JM, Rakhorst G. Normothermic ex vivo lung perfusion of non-heart-beating donor lungs in pigs: from pretransplant function analysis towards a 6-h machine preservation. Transpl Int. 2006;19(7): 589-93.

11. Cypel M, Yeung JC, Hirayama S, et al. Technique for prolonged normothermic ex vivo lung perfusion. J Heart Lung Transplant. 2008;27(12):1319-25.

12. Hennington MH, D'Armini AM, Lemasters JJ, Egan TM. Cadaver lungs for transplantation. Effect of ventilation with alveolar gas. Transplantation. 1996;61(7):1009-14.

13. Land WG. Transfusion-related acute lung injury: the work of damps. Transfus Med Hemother. 2013;40(1):3-13.

14. Petak F, Habre W, Hantos Z, Sly PD, Morel DR. Effects of pulmonary vascular pressures and flow on airway and parenchymal mechanics in isolated rat lungs. J Appl Physiol (1985). 2002;92(1): 169-78.

15. Broccard AF, Vannay C, Feihl F, Schaller MD. Impact of low pulmonary vascular pressure on ventilator-induced lung injury. Crit Care Med. 2002;30(10):2183-90.

16. Linacre V, Cypel M, Machuca T, et al. A positive left atrial pressure is important during ex vivo lung perfusion. J Heart Lung Transplant. 2014;33(4):S27-8.

17. Yeung JC, Cypel M, Machuca TN, et al. Physiologic assessment of the ex vivo donor lung for transplantation. J Heart Lung Transplant. 2012;31(10):1120-6.

18. Wallinder A, Ricksten SE, Hansson C, et al. Transplantation of initially rejected donor lungs after ex vivo lung perfusion. J Thorac Cardiovasc Surg. 2012;144(5):1222-8.

19. Wallinder A, Ricksten SE, Silverborn M, et al. Early results in transplantation of initially rejected donor lungs after ex vivo lung perfusion: a case-control study. Eur J Cardiothorac Surg. 2014;45(1):40-4. discussion 44-45.

20. Mulloy DP, Stone ML, Crosby IK, et al. Ex vivo rehabilitation of non-heart-beating donor lungs in preclinical porcine model: delayed perfusion results in superior lung function. J Thorac Cardiovasc Surg. 2012;144(5):1208-15. 
21. Cypel M, Yeung JC, Liu M, et al. Normothermic ex vivo lung perfusion in clinical lung transplantation. $\mathrm{N}$ Engl $\mathrm{J}$ Med. 2011;364(15):1431-40.

22. Cypel M, Yeung JC, Machuca T, et al. Experience with the first 50 ex vivo lung perfusions in clinical transplantation. $\mathrm{J}$ Thorac Cardiovasc Surg. 2012;144(5):1200-6.

23. Tikkanen JM, Cypel M, Machuca TN, et al. Functional outcomes and quality of life after normothermic ex vivo lung perfusion lung transplantation. J Heart Lung Transplant. 2015;34(4):547-56.

24. Aigner C, Slama A, Hotzenecker K, et al. Clinical ex vivo lung perfusion-pushing the limits. Am J Transplant. 2012;12(7): 1839-47.

25. Sanchez PG, Davis RD, D'Ovidio F, et al. The novel lung trial oneyear outcomes. J Heart Lung Transplant. 2014;33(4):S71-2.

26. Machuca TN, Mercier O, Collaud S, et al. Lung transplantation with donation after circulatory determination of death donors and the impact of ex vivo lung perfusion. Am J Transplant. 2015;15(4): 993-1002.

27. Machuca TN, Hsin MK, Ott HC, et al. Injury-specific ex vivo treatment of the donor lung: pulmonary thrombolysis followed by successful lung transplantation. Am J Respir Crit Care Med. 2013;188(7):878-80.

28. Inci I, Yamada Y, Hillinger S, Jungraithmayr W, Trinkwitz M, Weder W. Successful lung transplantation after donor lung reconditioning with urokinase in ex vivo lung perfusion system. Ann Thorac Surg. 2014;98(5):1837-8.

29. Andreasson A, Karamanou DM, Perry JD, et al. The effect of ex vivo lung perfusion on microbial load in human donor lungs. J Heart Lung Transplant. 2014;33(9):910-6.

30. Inci I, Hillinger S, Arni S, Kaplan T, Inci D, Weder W. Reconditioning of an injured lung graft with intrabronchial surfactant instillation in an ex vivo lung perfusion system followed by transplantation. J Surg Res. 2013;184(2):1143-9.

31. Frank JA, Briot R, Lee JW, Ishizaka A, Uchida T, Matthay MA. Physiological and biochemical markers of alveolar epithelial barrier dysfunction in perfused human lungs. Am J Physiol Lung Cell Mol Physiol. 2007;293(1):L52-9.

32. Fischer S, Liu M, MacLean AA, et al. In vivo transtracheal adenovirus-mediated transfer of human interleukin-10 gene to donor lungs ameliorates ischemia-reperfusion injury and improves early posttransplant graft function in the rat. Hum Gene Ther. 2001;12(12):1513-26.
33. Martins S, de Perrot M, Imai Y, et al. Transbronchial administration of adenoviral-mediated interleukin-10 gene to the donor improves function in a pig lung transplant model. Gene Ther. 2004;11(24): 1786-96.

34. Cypel M, Liu M, Rubacha M, et al. Functional repair of human donor lungs by il-10 gene therapy. Sci Transl Med. 2009;1(4):4ra9.

35. Cypel M, Rubacha M, Yeung J, et al. Normothermic ex vivo perfusion prevents lung injury compared to extended cold preservation for transplantation. Am J Transplant. 2009;9(10):2262-9.

36. Yeung JC, Wagnetz D, Cypel M, et al. Ex vivo adenoviral vector gene delivery results in decreased vector-associated inflammation pre- and post-lung transplantation in the pig. Mol Ther. 2012;20(6): 1204-11.

37. Raper SE, Chirmule N, Lee FS, et al. Fatal systemic inflammatory response syndrome in a ornithine transcarbamylase deficient patient following adenoviral gene transfer. Mol Genet Metab. 2003;80(12):148-58.

38. Kaneda H, Waddell TK, de Perrot M, et al. Pre-implantation multiple cytokine mrna expression analysis of donor lung grafts predicts survival after lung transplantation in humans. Am J Transplant. 2006;6(3):544-51.

39. Anraku M, Cameron MJ, Waddell TK, et al. Impact of human donor lung gene expression profiles on survival after lung transplantation: a case-control study. Am J Transplant. 2008;8(10): 2140-8.

40. Ray M, Dharmarajan S, Freudenberg J, Zhang W, Patterson GA. Expression profiling of human donor lungs to understand primary graft dysfunction after lung transplantation. Am J Transplant. 2007;7(10):2396-405.

41. Kelley SO, Mirkin CA, Walt DR, Ismagilov RF, Toner M, Sargent $\mathrm{EH}$. Advancing the speed, sensitivity and accuracy of biomolecular detection using multi-length-scale engineering. Nat Nanotechnol. 2014;9(12):969-80.

42. Yeung JC, Zamel R, Bai X, et al. Towards donor lung recoverygene expression changes during ex vivo lung perfusion. J Heart Lung Transplant. 2015;34(4):S39-40.

43. Hsin MK, Zamel R, Cypel M, et al. Metabolic profiling of perfusate from clinical ex vivo lung perfusion yields potential biomarkers of early lung transplant outcomes. J Heart Lung Transplant. 2014;33(4):S96-7. 